\title{
Isıl Yabancı Ot Kontrolü İçin Özel İmal Edilen Gaz Memelerinin Performansı
}

\author{
Selçuk ARSLAN ${ }^{\mathscr{P}}$ (D) , Çăgdaş TURALOĞLU2 ${ }^{(\mathbb{D}}$, Nihat TURSUN ${ }^{3}$ (D) \\ ${ }^{1}$ Bursa Uludağ Üniversitesi, Ziraat Fakültesi, Biyosistem Mühendisliği Bölümü, Bursa, ${ }^{2}$ Bursa Uludağ Üniversitesi, Fen Bilimleri Enstitüsü, \\ Biyosistem Mühendisliği Anabilim Dalı, Bursa, ${ }^{3}$ Malatya Turgut Özal Üniversitesi, Ziraat Fakültesi, Bitki Koruma Bölümü, Malatya \\ ${ }^{1}$ https://orcid.org/0000-0003-4636-1234, ${ }^{2}$ https://orcid.org/0000-0002-8003-7270, ${ }^{3 h t t p s: / / o r c i d . o r g / 0000-0002-8765-0326 ~}$ \\ $\bowtie$ : sarslan@uludag.edu.tr
}

\section{ÖZET}

$\mathrm{Bu}$ çalışmanın amacı, yabancı ot kontrolünde kullanılan alev makinelerinde kullanılabilecek ve ticari gaz memelerine göre daha uygun bir gaz memesi geliştirmektir. Bu amaçla, üç farklı meme tasarlanmış ve 1.0-3.0 bar aralığında basınç-debi karakteristikleri gravimetrik olarak belirlenmiştir. Üç delikli $1 \mathrm{~mm}$ çaplı memenin (Tip1) 1.5-2.5 bar basınçlarda aralığında, yabancı ot mücadelesinde genellikle gerekli olan 40-130 $\mathrm{kg} \mathrm{ha}^{-1}$ propan (LPG) dozların uygulayabileceği bulunmuştur. Bu meme tipi, ticari gaz memesine göre düşük dozlar için gerekli ilerleme hızını azaltmış, yüksek dozlar için gerekli olanı ise yükseltmiştir. Böylece ticari gaz memesi için 2.0 bar basınçta gerekli olan 1.8-8.1 $\mathrm{km} \mathrm{h}^{-1}$ aralığındaki hız sınırı 3.5-6.5 $\mathrm{km} \mathrm{h}^{-1}$ aralığına çekilmiştir. Yüksek dozlarda gerekli olan ilerleme hızları biraz artırılmış olduğundan uygulamada özel imal edilen gaz memesi kullanılarak alev makinesinin alan iş başarısının artırılabileceği bulunmuştur. En düşük dozda ise ilerleme hızının düşürülmüş olması alan iş başarısını azaltacak olsa da yabancı otların aleve maruz kalma süresi \%20 kadar artacağı için alev uygulamasının ısıl etkinliğini potansiyel olarak artıracaktır. Tip2 ve Tip3 memeler, delik çapları küçük olduğu için traktöre bağlanacak bir alev makinesi için uygun bulunmamıştır. Sonuç olarak, yabancı ot mücadelesinde kullanılacak alev başlıkları için daha uygun bir ürün (Tip1) elde edilebilmiştir.

\section{Araştırma Makalesi}

Makale Tarihçesi

Geliş Tarihi : : 17.12.2018

Kabul Tarihi : 18.01.2019

Anahtar Kelimeler

Yabancı Ot Mücadelesi

Alev Başlı̆̆

Gaz Memesi

Gaz Dozu

\section{The Performance of Specially-Built Gas Nozzles for Thermal Weed Control}

\section{ABSTRACT}

The aim of this study was to develop a gas nozzle that can be used more appropriately in flame weeding compared to commercial ones. For this purpose, three different types of nozzles were built, tested at gas pressures of 1.0-3.0 bar, and flowrate-pressure characteristics were determined using gravimetric method. Among the gas nozzles built, 3-hole $1 \mathrm{~mm}$ diameter nozzle (Type1) was found to be appropriate to provide targeted LPG gas doses of $40-130 \mathrm{~kg} \mathrm{ha}^{-1}$ at a pressure range of 1.5-2.5 bar. This nozzle decreased the high ground speeds for low gas doses that had to be applied using the commercial gas nozzle, and increased the low ground speeds for high gas doses. As a result, the required ground speed range of $1.8^{-8} 8.1 \mathrm{~km} \mathrm{~h}^{-1}$ for the commercial nozzle was improved to $3.5-6.5 \mathrm{~km} \mathrm{~h}^{-1}$ at an operating gas pressure of 2.0 bar. Field capacity can be increased using the speciallybuilt nozzle since ground speeds were increased at high doses. Also, the exposure time of weeds to heat was increased about $20 \%$ at low doses, potentially increasing the flaming efficiency. Due to small hole diameters, Type 2 and Type 3 were not appropriate for tractor-mounted flame weeders. It was concluded that the result of the study to develop specially-built gas nozzle (Type1) as an alternative to commercial ones was positive.

\section{Research Article}

$\begin{array}{ll}\text { Article History } \\ \text { Received } & : 17.12 .2018 \\ \text { Accepted } & : 18.01 .2019\end{array}$

Keywords

Weed Control

Torch

Propane Nozzle

Gas Dose

To Cite : Arslan S,Turaloğlu Ç, Tursun N 2019. Isıl Yabancı Ot Kontrolü İçin Özel İmal Edilen Gaz Memelerinin Performansı. KSÜ Tarım ve Doğa Derg 22(3): 430-435. DOI: 10.18016/ksutarimdoga.vi.498128. 


\section{GİRIŞ}

Isıl teknikler için alev uygulaması, tarımda yabancı ot kontrolü için uzun yıllardır bilinen bir yöntemdir. Alev makinelerinin kullanımı dünyada çok geniş bir uygulama alanı bulmamıştır. Bunun en önemli nedeni, kimyasal ilaçlamanın hızlı, etkin ve göreceli olarak ucuz olmasıdır. Alevle yabancı ot mücadelesinin yayginlaşmamasının diğer nedenleri arasında, basınçlı tüp kullanılmasının verdiği çekinceler, anızın yanma olasılığı nedeniyle koruyucu toprak işleme ile uyumlu olmaması sayılabilir. Ancak, herbisitler de pahalı olabilmektedir ve istenmeyen yan etkileri bulunmaktadır. Kimyasal ilaç kullanımının pestisit kalıntısı sorunu yarattığı iyi bilinmektedir. İlaçlar, hedeflenen yabancı otlar dışında başka canlılara da etki etmekte ve yabancı otların kimyasallara dayanıklılığına neden olmaktadır. Organik tarımda kimyasal ilaç kullanımı yasaklanmıştır.

Literatür, farklı kültür bitkilerinin yetiştiriciliğinde karşılaşılan yabancı otların hangi düzeyde (\%) kontrol edilebildiğini belirlemek için farklı dozlarda (kg ha-1) gaz kullanılarak yapılan deneysel çalışmalara yoğunlaşmıştır. Birkaç çalışma ise alev makinesi geliştirilmesiyle ilgili ayrıntıları ele almıştır.

Alev uygulaması (alevleme); genel anlamda etkin ve güvenli kabul edilmektedir, ayrıca alev makineleri yapısal olarak basit ve sağlamdır (Merfield, 2011). Çapa ile yapılan mekanik yabancı ot mücadelesinde toprağa yapılan etki nedeniyle toprak içinde gömülü durumdaki yabancı otlar yüzeye çlkmakta ve çimlenme şansı bulmaktadır. Bu bağlamda, alev uygulamasının yalnız ilaçlamaya göre değil, çapalamaya göre de olumlu bir yanı bulunmaktadır (Wszelaki ve ark., 2007). Alevleme, özellikle kimyasal ilaç kullanımının yasak olduğu organik tarım yetiştiriciliğinde daha yaygındır, ancak geleneksel üretimde de uygulama potansiyelinin olduğu düşünülmektedir (Parish, 1990; Bond ve Grundy, 2001). Alevleme anlık yapılan yüksek bir ısı uygulama işleminden ibarettir ve kızılöetesi ve buhar makinesi uygulamalarına göre en iyi uygulama potansiyeli olduğu bulunmuştur (Rifai ve ark., 2003). Ne var ki alevleme işleminde başarıyı etkileyen teknik ve agronomik olmak üzere çok sayıda faktör bulunmaktadır (Sivesind ve ark., 2009). Alev uygulaması için yakılan gaz olarak propan (LPG) kullanılmaktadır (Ulloa ve ark., 2011).

Alevleme tekniği ile yapılan araştırmalar sonucunda alev başlığının yerden optimum yüksekliği $(20-25 \mathrm{~cm})$, alev başlığının düşey düzleme göre uygulama açısı (30$45^{\circ}$ ), alevin yabancı otlara hangi yükseklikte çarpması gerektiği $(5 \mathrm{~cm}$ ) bulunmuştur (Kang, 2001; Arslan ve ark., 2016). Alev uygulamasında ortaya çıkan ısı enerjisi bitki dokusuna geçmekte (Lague ve ark., 2001), bitki hücrelerindeki sıcaklık $50{ }^{\circ} \mathrm{C}$ 'den fazla olursa proteinlerde pıhtılaşma (Lague ve ark., 2001),
$100{ }^{\circ}$ C'yi aşarsa hücre zarında patlatma oluşmaktadır (Morelle, 1993). Alev ısısı etkisinde kalan yabancı otların beslenmesi engellenmiş olduğundan ölmektedirler (Rifai ve ark., 1996).

Ülkemizde ısıl yabancı ot kontrolü ile ilgili çalışmalar çok sınırlıdır. Aynı şekilde, literatürde alev başlıklarında kullanılan gaz memeleriyle ilgili çok az bilgi bulunmaktadır. Alev başlıklarında yerli imal edilen ticari gaz memeleri kullanılabileceğine ilişkin bulgular vardır (Güleç ve ark., 2015). Ancak, yerli ticari gaz memeleriyle yapılan uygulamalarda, basınç kontrollü alev makinesi kullanırken traktör ilerleme hız aralığ bulunmuştur. Bu hız değerleri, düşük hızlarda alan iş kapasitesini düşürmekte, yüksek hızlarda ise alevin yabancı ota etki süresini kısaltmaktadır (Tursun ve ark., 2017). Bunun için farklı meme konfigürasyonları denenmeli ve yabancı ot kontrolü için kullanılan alev başlıklarına daha uygun olacak gaz memelerinin geliştirilmesine çalışılmalıdır. Bu çalışmanın amacı, ticari gaz memelerine alternatif olabilecek çok delikli gaz memeleri imal etmek ve traktöre asılır tip alev makineleriyle yapılan yabancı ot mücadelesinde kullanılıp kullanılamayacağını belirlemektir.

\section{MATERYAL ve METOT}

$\mathrm{Bu}$ araştırmada tek delikli konik huzmeli gaz memesine alternatif olabilecek bazı tasarımlar üzerinde durulmuştur. Bu çerçevede, montaj boyutları sanayide şalamo (pürmüz) olarak bilinen gaz başlıklarındaki ticari memelerle aynı olan ve 2 , 3 , ve 5 delikli memeler tasarlanmıştır. $\mathrm{Bu}$ memeler, dalma erozyon yöntemiyle imal edilmiştir. Her bir meme, önceki bir çalışmada kullanılan gaz (LPG) yakma düzeneğine benzer bir sistem kullanılarak test edilmiştir (Güleç ve ark., 2015). İmal edilen çok delikli memeler Çizelge 1'de verilmiştir.

Çizelge 1. Özel imal edilen gaz memelerinin kodları ve özellikleri

\begin{tabular}{|c|c|}
\hline Kodu & Delik çapı ve sayısı \\
\hline Tip1 & $1.0 \mathrm{~mm}$ 3 delikli \\
\hline Tip2 & $0.8 \mathrm{~mm}$ 3 delikli \\
\hline Tip3 & $0.5 \mathrm{~mm} 5$ delikli \\
\hline
\end{tabular}

Test edilen gaz memelerinin debisi 0.5, 1.0, 1.5, 2.0, 2.5 ve 3.0 bar basınç değerinde 3 tekrarlı olacak şekilde ölçülmüştür. Debi ölçümü için referans yöntem olan ağırlık ölçüm yöntemi kullanılmıştır. Bunun için tüp ağırlığ $50 \mathrm{~kg} \pm 1 \mathrm{~g}$ hassasiyeti olan bir elektronik terazi ile tartılmış, en az bir dakikalık gaz yakma sonunda tüp ağırlığındaki azalma ölçülmüştür. Ağırlık ve zaman ölçümleri süresince ( $\mathrm{g} \mathrm{s}^{-1}$ birimiyle) tüketilen gazın kütlesel debisi $\left(\mathrm{kg} \mathrm{h}^{-1}\right)$ hesaplamıştır. Her bir meme tipi için debi, üç tekrarlı ölçümlerin ortalaması alınarak bulunmuştur. 
Gaz yakma süresince alev huzmesinin nasıl yayıldığı bir termal kamera (Testo 885) yardımıyla gözlenmiş, huzmenin genişliği ve uzunluğunun yeterli olup olmayacağı değerlendirilmiştir.

Alevle yabancı ot kontrolü için yapılan bilimsel araştırmalarda $15^{-90} \mathrm{~kg} \mathrm{ha}^{-1}$ arasındaki dozların kullanıldığı ve farklı yabancı otların alevlemeye gösterdiği tepkinin belirlendiği görülmektedir (Rifai ve ark., 2003; Sivesind ve ark., 2009; Ulloa ve ark., 2011). $\mathrm{Bu}$ çalışmada, imal edilen özel gaz memelerinde elde edilecek dozların önceki araştırıcıların sıklıkla kullandığı bu dozlarla aynı olması veya yakın olması hedeflenmiştir. Uygulanması istenen doz değerleri için gerekli kalibrasyon hesaplamaları, ilaçlama makinalarına benzer şekilde yapılmıştır. Alev başlığından $20 \mathrm{~cm}$ uzaklıkta ölçülen alev huzme genişliği, etkin iş genişliği olarak alınmıştır. Huzme genişliği $(\mathrm{m})$ ve debi $\left(\mathrm{kg} \mathrm{h}^{-1}\right)$ değerleri kullanılarak istenen bir doz değeri $\left(\mathrm{kg} \mathrm{ha}^{-1}\right)$ için gerekli makine ilerleme hızı $\left(\mathrm{km} \mathrm{h}^{-1}\right)$ hesaplanmıştır. Böylece, arazi koşullarında yapılacak uygulamada her bir meme tipi için basınç (P), ilerleme hızı (V) ve gaz dozu (D) arasındaki ilişkileri gösteren grafikler elde edilmiş, makine kalibrasyonunun hangi sinirlarda yapılabileceği bulunmuştur. Memeler arasındaki farklar karşılaştırılmış ve yabancı ot alevleme tekniğinde gerekli görülen gaz dozlarının elde edilip edilmediği her bir meme tipi için belirlenmiştir.

\section{BULGULAR ve TARTIŞMA}

Özel imal edilen tüm gaz memelerinin basınç-debi ilişkisi doğrusal bulunmuştur. Tüm memelerden elde edilen $\mathrm{r}^{2}$ değerleri 0.99 ve üzerindedir. Şekil 1, Tip1 meme için bulunan debi-basınç davranışını göstermektedir.

Şekil 2-4; ilerleme hızı ve basınç değerleri göz önüne alınarak bulunan LPG gaz dozlarını sirasiyla Tip1, Tip2 ve Tip3 gaz memesi için göstermektedir.

Şekil 2-4, her bir meme için sabit bir basınçta ilerleme hızı arttıkça, uygulanacak LPG dozunun azalacağını göstermektedir. Sabit ilerleme hızında ise basınç arttıkça LPG dozunda bir miktar artış olmaktadır. Alev makinesinin ilerleme hızının LPG gaz dozuna etkisi, basıncın etkisinden daha fazladır. İlerleme hızı, sabit bir basınç için geniş bir aralıkta değiştirilerek çok farklı gaz dozları elde edilebilirken gaz basıncı geniş bir aralıkta değiştirilememektedir.

Laboratuvar denemeleri 0.5 bar'dan başlayarak 0.5 bar aralıkla yapılmıştır. Ancak, düşük (0.5 bar) ve yüksek (3.0 bar) basınçta değerlendirmeye uygun olmayan durumlar bulunmuştur.

Termal kamera görüntülerine göre, basincın 1.5-2.5 bar aralığında, alev başlığından 20-25 cm uzaklıkta alev huzmesi genişliği yaklaşı $25 \mathrm{~cm}$ kadar ölçülmüştür. Gaz basıncı 1.5 bar'ın altında düştüğünde huzme genişliği belirgin bir şekilde azaltmakta ve huzme uzunluğu kısalmaya başlamaktadır. Yüksek basınçta $(3.0$ bar $)$ ise küçük delikli meme kullanıldığında elde edilen debi, 2.0 bar ile karşılaştırıldığında bir artış göstermemiştir. Buna göre, küçük delikli memeler kullanılarak yüksek gaz basınçlarında çalışılamayacağı, bu yüzden gerekli yüksek gaz dozlarını elde etmenin mümkün olmayacağı sonucuna varılmıştır.

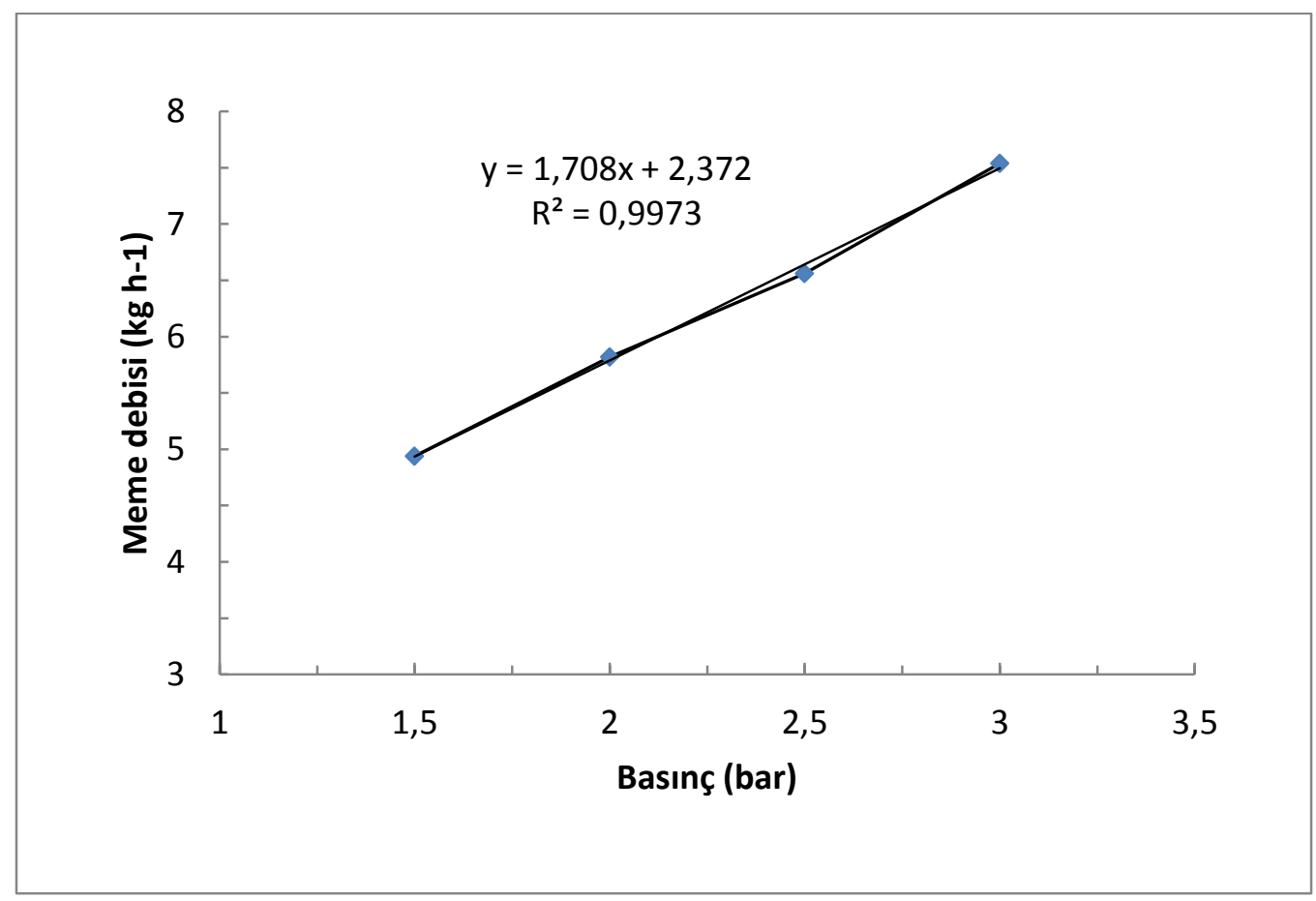

Şekil 1. Tip1 memede basınç-debi ilişkisi 


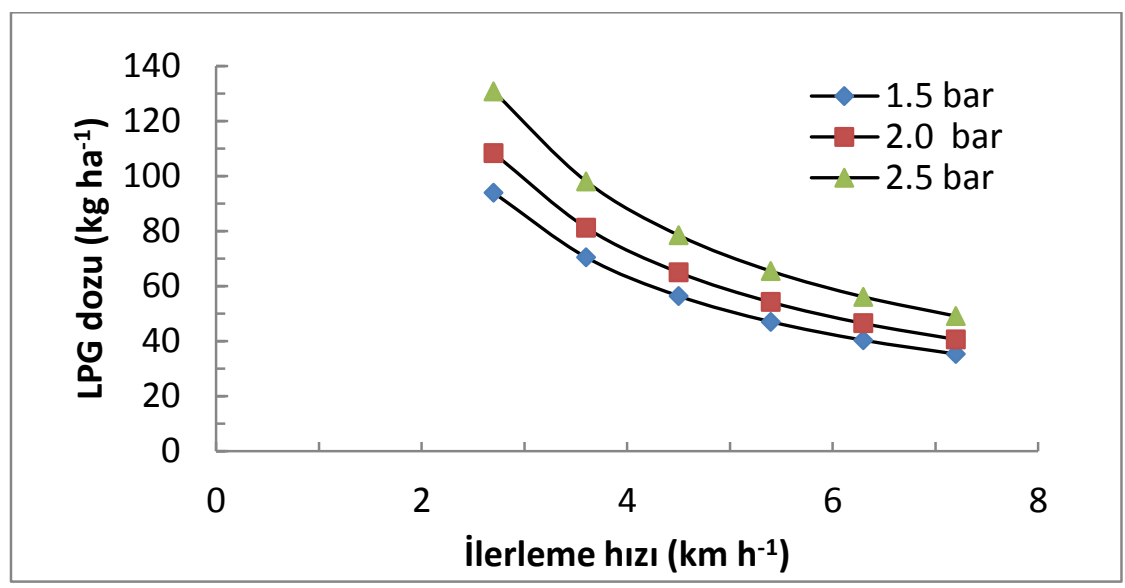

Şekil 2. Tip1 memede ilerleme hızı-basınç ve gaz dozu ilişkisi

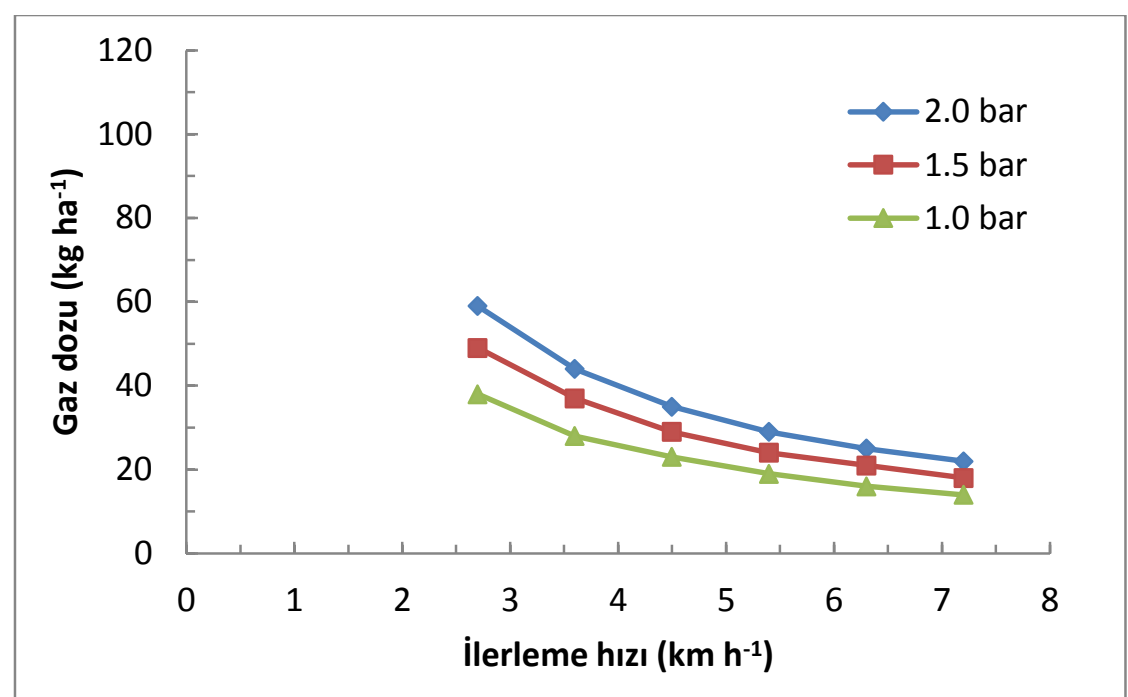

Şekil 3. Tip2 memede ilerleme hızı-basınç ve gaz dozu ilişkisi

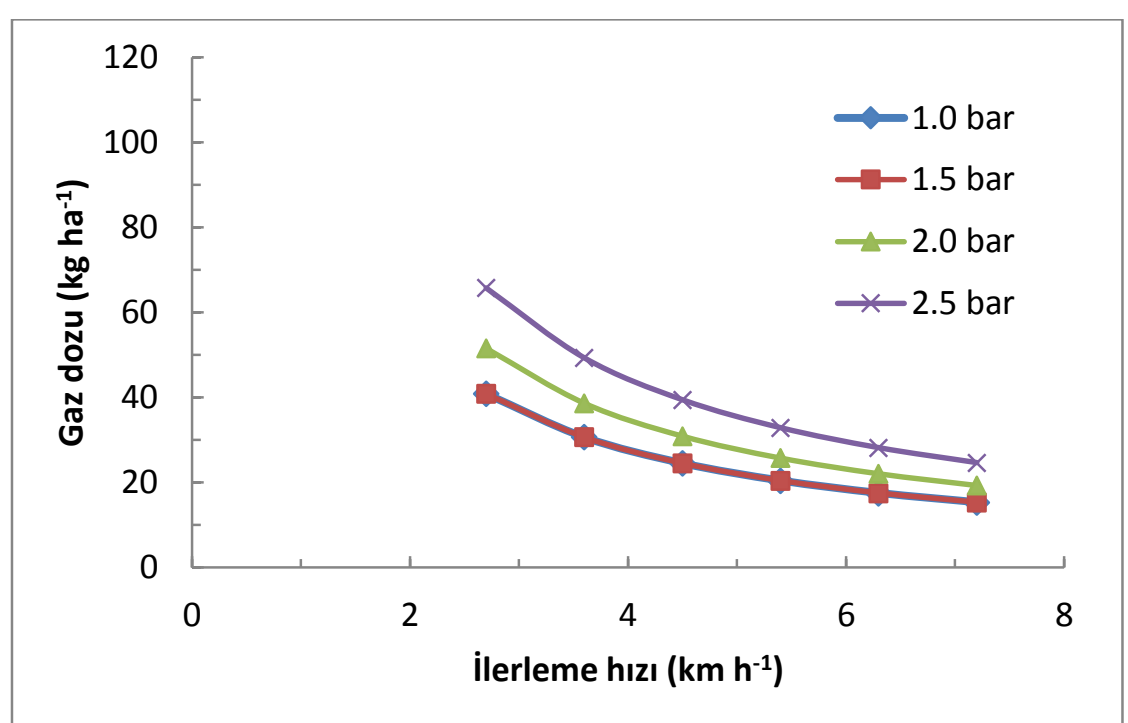

Şekil 4. Tip3 memede ilerleme hızı-basınç ve gaz dozu ilişkisi

Örneğin, Tip2 memede 2.0 bar'ın üzerine çıkılamamıştır (Şekil 3). 1.5 bar'dan küçük basınçlarda ise tüm memelerde yeterli gaz debisi elde edilememiştir. Örneğin, Şekil 2'de görüldüğü gibi, basınç değeri $1.0 \mathrm{~mm}$ delikli memede 3.0 bar'a kadar çıkabilmektedir, ancak 0.8 ve $0.5 \mathrm{~mm}$ delikli memelerde 3.0 bar basınçta debide herhangi bir artış olmamış, debi-basınç arasındaki doğrusal ilişki bozulmuştur. Bu nedenle, Şekil 3 ve Şekil 4'te 3.0 bar için veri bulunmamaktadır.

Aynı basınç değerinde elde edilebilecek gaz dozu en yüksek Tip1 memede bulunmuştur. Bunu Tip 2 ve Tip 
3 izlemektedir (Şekil 2-4). Aynı meme tipinde farklı basınçlar uygulanarak Tip1 ile yaklaşık 40-130 kg ha' 1, Tip2 ile 15-60 kg ha-1 ve Tip 3 ile 10-70 kg ha-1 LPG normu elde edilebilir. Tip 2 ve Tip 3 memelerin gaz dozu uygulaması açısından birbirine benzer sonuçlar verdiği söylenebilir. Literatür, dar yapraklı otlar için gaz dozu gereksiniminin $90 \mathrm{~kg}$ ha-1'dan çok daha yüksek olabileceğini, ancak geniş yapraklı yabancı otlar için erken dönemde yapılan uygulamada 40-60 kg ha $^{-1}$ dozun yeterli olabileceğini rapor etmektedir (Wszelaki ve ark., 2007, Rifai ve ark., 1996, Ullua ve ark., 2011, Sivesind ve ark., 2009, Tursun 2016). Tip2 ve Tip3 memeleri kullanarak, özellikle dar yapraklı yabancı otlar için gerekli olan yüksek dozların elde edilemeyeceği bulunmuştur. Ancak, geniş yapraklı otların yaygın olduğu ve dar yapraklı yabancı otların verimi baskılamadığı durumlarda bu tip memelerin kullanılması uygun olabilir.

Tip 1 ve Tip 2 memelerin kullanımını sınırlayan ikinci faktör ise ilerleme hızı gereksinimi olarak bulunmuştur. $\mathrm{Bu}$ memelerle elde edilecek en yüksek dozlarda makine ilerleme hızını 2.5-3 $\mathrm{km} \mathrm{h}^{-1}$ değerine kadar düşürmek gerekmektedir. Uygulamada, 30-40 $\mathrm{kg} \mathrm{ha}^{-1}$ dozun altındaki dozların gerekli olduğu durumlarla sıklıkla karşılaşılmayacağ değerlendirilerek gerek Tip2 gerekse Tip3 memenin alevleme tekniği açısından traktöre bağlanan bir makine için uygun olmayacağı sonucuna varılmıştır. Ancak, bu memeler, düşük hızlarda çalıştırılabileceği için elle çekilir veya sırtta taşınır alev makinelerine uyarlanabilir. Alev huzmesi uzunluğu 1.5-2.5 bar aralığında tüm memeler için $40 \mathrm{~cm}$ 'den fazla bulunmuştur. Uygulama yüksekliğinin $25 \mathrm{~cm}$ 'den fazla olmayacağı öngörülerek huzme uzunluğunun tüm memeler için yeterli olduğu bulunmuştur. Alev başlığından $20 \mathrm{~cm}$ uzaklıktaki huzme genişliği de 25 cm'den az değildir.

Tip 1 meme, 1.5-2.5 bar basınç aralığında yaklaşık olarak 2.7-6.5 $\mathrm{km} \mathrm{h}^{-1} \mathrm{hlz}$ aralığında 40-130 $\mathrm{kg} \mathrm{ha}^{-1} \mathrm{doz}$ uygulamasını sağlayabilmektedir (Şekil 2). Buna göre, Tip1 gaz memesi, gerek dar yapraklı gerekse geniş yapraklı otlarla mücadele için en uygun meme tipi olarak bulunmuştur. Alev uygulamasında yüksek makine ilerleme hızı, yabancı otların ısıdan etkilenme süresini azaltacağ 1 için istenmeyen bir durumdur. Isıl etkiyi artırmak için ilerleme hızının olabildiğince düşük olması tercih edilebilir, ancak bu da makinenin birim zamanda işleyeceği alanı minimize edeceği için makine işletmeciliği açısından istenmeyecektir. $\mathrm{Bu}$ bağlamda, Tip 1 meme 1.5 bar basınçta ilerleme hızını çok yüksek tutmadan düşük dozların $\left(35-45 \mathrm{~kg} \mathrm{ha}^{-1}\right)$ uygulaması için kullanılabilir. Ancak alan iş başarısını artırmak açısından mümkün olan en yüksek basınçta (2.5 bar) çalışılması önerilebilir. En yüksek basınçta yaklaşık $3.5^{-} 6.5 \mathrm{~km} \mathrm{~h}^{-1}$ ilerleme hızlarında $55^{-9} 95 \mathrm{~kg} \mathrm{ha}$ ${ }^{1}$ doz uygulaması mümkün görünmektedir.

\section{SONUÇ ve ÖNERILER}

Ticari olarak bulunabilen ve sanayide kullanılmakta olan gaz memelerini kullanmak yerine, yabanc1 ot alevlemesi için kullanılabilecek özel imal edilecek gaz memeleri araştırılmıştır. Bu amaçla, dalma erozyon yöntemiyle üç farklı gaz memesi tasarlanmıştır: Tip1 (1.0 mm 3 delikli), Tip2 (0.5 mm 5 delikli) ve Tip3 (0.8 mm 3 delikli). Bunlar içinde Tip1 kodlu memenin, yabancı ot alevlemesi için en uygun olacağı bulunmuştur. Tip1 gaz memesi, alev başlığ ile birlikte $25 \mathrm{~cm}$ iş genişliği ve yaklaşık $40 \mathrm{~cm}$ etkin alev uzunluğu sağlamaktadır. Bu meme tipi; 1.5 ile 2.5 bar arasında $2.7-6.5 \mathrm{~km} \mathrm{~h}^{-1}$ hiz aralığında 40-130 $\mathrm{kg} \mathrm{ha}^{-1}$ doz uygulamasinı yapabilecektir. Tip2 ve Tip3 meme, iş başarısını düşürmeden traktörle yapılacak çalışmalar için uygun bulunmamıştır, ancak, elle çekilir veya sırtta taşınır bir alev makinesi için uygun olabilirler. Delik çapı $1 \mathrm{~mm}$ 'den az olan memelerin traktöre asılır tip bir alevleme makinesi için uygun olmayacağı bulunmuştur.

Bu çalışmada imal edilen meme tipleri, piyasada yaygın olarak kullanılan meme tiplerinde olduğu gibi konik huzmelidir. Bundan sonraki araştırmalar, çok delikli memelerde deliklerinin püskürtme açılarının, kullanılacak alev başlığının geometrisiyle daha uyumlu hale getirilmesi üzerine odaklanabilir. Ek olarak, ilaçlama makinelerinde sıkça kullanılan yelpaze huzmeli memelere benzer gaz memelerinin de geliştirilmesi, ısı dağılımını geliştirecektir.

\section{TEŞEKKÜR}

$\mathrm{Bu}$ çalışmayı destekleyen Türkiye Bilimsel ve Teknolojik Araştırma Kurumu (TÜBİTAK)'na teşekkür ederiz (Proje No: 213O109).

\section{KAYNAKÇA}

Arslan S, Tursun N, Kurtulmuş F, Güleç D, 2016. Use of Thermal Images for Optimizing Burner Height, Operating Pressure, and Burner Angle of a Weed Flamer. Agronomy Research, 14(1): 14-24.

Bond W, Grundy AC 2001. Non-Chemical Weed Management in Organic Farming Systems. Weed Research, 41: 383-405.

Güleç D, Arslan S, Tursun N 2015. Farklı Gaz Memelerinin Alev Makinesi Başlıkları Geliştirilmesi için Kullanılma Olanakları. Tarım Makinaları Bilimi Dergisi, 11(3): 231-237.

Kang WS 2001. Development of a Flame Weeder. Transactions of the ASAE, 44(5): 1065-1070.

Lague C, Gill J, Peloquin G 2001. Thermal Control in Plant Protection. In: Vincent, C., Panneton B, Fleurat-Lessard F. (Eds.), Physical Control Methods in Plant Protection. Springer-Verlag, Berlin, Germany, pp. 35-46.

Merfield CN 2010. Thermal Weed Management for Crop Production. www.merfield.com (Erişim tarihi: 27 Kasım 2014). 
Morelle B 1993. Thermal Weed Control and its Application in Agriculture and Horticulture. In: Communications of the 4th International Conference IFOAM, Non-chemical Weed Control, Dijon, France, 111-116.

Önler E, Çelen IH, Kılıç E 2013. Effects of FLAME on Xanthium Strumarium at Flame Weeding Application. Russe University, Bulgaria.

Özvardar S, Çelen İH, Önler E 2010. Alevli Mücadelede Alevin Bazı Yabancı Ot Türlerine Etkisi. 26. Tarımsal Mekanizasyon Ulusal Kongresi, 22-23-Eylül, Hatay.

Parish S 1990. A Review of Non-chemical Weed Control Techniques. Biol. Agric. Hort., 7: 117-137.

Rifai MN, Zikla T, Mojzis M 1996. Flame and Mechanical Cultivation for Weed Control. Zemedelska Technica 42: 109-113.

Rifai MN, Miller J, Gadus J, Otepka P, Kosik L 2003. Comparison of Infrared, Flame and Steam Units for Their Use in Plant Protection. Res. Agr. Eng., 49: 65-73.
Sivesind EC, Leblanc ML, Cloutier DC, Seguin P, Stewart KA 2009. Weed Response to Flame Weeding at Different Developmental Stages. Weed Technology, 23:438-443.

Tursun N, Arslan S, Demir Z, Karlıdağ H 2017. Kayısı Bahçelerinde Yabancı Otlara Karşı Herbisitlere Alternatif Mücadele Yöntemlerinden Alevleme ve Örtücü Bitkilerin Kullanım Olanaklarının Araştırılması. Sonuç Raporu, Proje Kodu: TUBİTAK 1001, Proje No: 213 O 109.

Ulloa SM, Datta A, Bruening C, Neilson B, Miller J. Gogos G, Knezevic SZ 2011. Mazie Response to Broadcast Flaming at Different Growth Stages: Effects on Growth, Yield and Yield Components. European J. of Agronomy, 34:10-19.

Wszelaki AL, Doohan DJ, Alexandrou 2007. Weed Control and Crop Quality in Cabbage [Brassica oleracea (capitata group)] and Tomato (Lycopersicon lycopersicum) Using a Propane Flamer. Crop Prot. 26: 134-144. 